
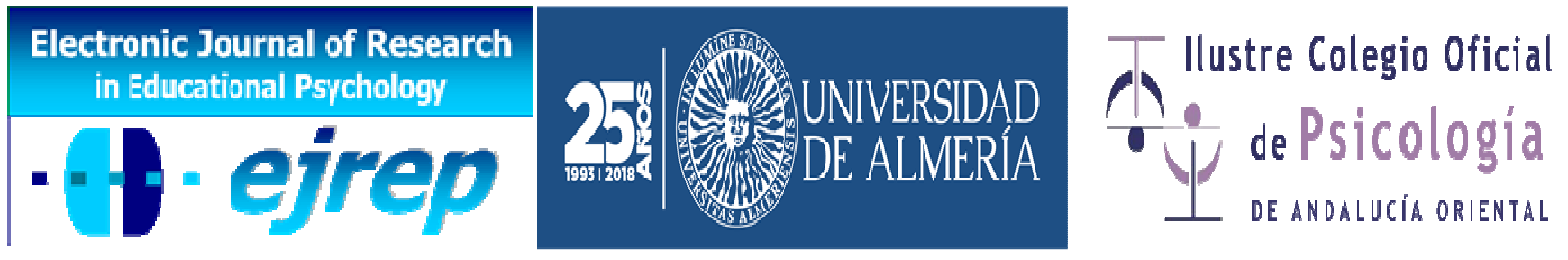

\title{
Effects of Achievement Goals on Students' Motivational beliefs and Coping Strategies: A Multiple Goals Perspective
}

\section{Nurcan Kahraman}

Independent Researcher

\section{Turkey}

Correspondence: Nurcan KAHRAMAN, Independent Researcher, Turkey E-mail: nurcan.kahraman@gmail.com

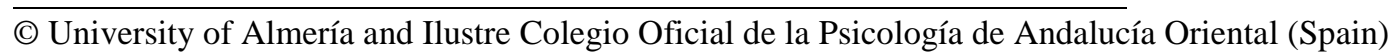




\begin{abstract}
Introduction. This study aims to explore the effect of students' adoption of approach goals; both mastery and performance approach goals and performance avoidance goals on their motivational beliefs and coping strategy use in science classes from multiple goals perspective. Students' motivational beliefs were examined in terms of self-efficacy and task-value beliefs while their coping strategy use was examined in terms of positive, projective, and denial coping and non-coping.
\end{abstract}

Method. The sample of this study consist 317 seventh grade students. Motivated Strategies for Learning Questionnaire was used to assess students' self-efficacy and task value. Besides, Achievement Goal Questionnaire and Academic Coping Inventory were used in the present study to assess students' motivational beliefs and coping strategies.

Results. The cluster analysis suggested four clusters of achievement goals: mastery-oriented goals (high mastery approach, low performance approach and avoidance goals), performanceoriented goals (high performance approach and avoidance, moderate mastery approach goals), approach oriented goals (high mastery and high performance approach, and less performance avoidance goals) and high multiple oriented goals (high mastery, high performance approach and high performance avoidance goals).

Discussion and Conclusion. According to the results, students with approach oriented goals and high multiple oriented goals are more likely to possess adaptive motivational beliefs and use positive coping strategies.

Keywords: multiple goals, self-efficacy, task value, coping strategies, science education 


\section{Resumen}

Introducción. Esta investigación tiene por objeto explorar el efecto de la adopción de metas de aproximación de los estudiantes, tanto de enfoque de maestría, enfoque de rendimiento y de evitación del rendimiento, en sus creencias motivacionales y uso de la estrategia de afrontamiento en las clases de ciencias desde una perspectiva de objetivos múltiples. Las creencias motivacionales de los estudiantes fueron examinadas en términos de autoeficacia y creencias de valor de tarea mientras que su uso de la estrategia de afrontamiento fue examinado en términos de afrontamiento positivo, proyectivo y de negación y no afrontamiento.

Método. La muestra de este estudio consiste en 317 estudiantes de séptimo grado. Se usó para evaluar la autoeficacia y el valor de la tarea de los estudiantes un Cuestionario de Estrategias Motivadas para el Aprendizaje. Además, un Cuestionario de objetivos de logro e inventario de afrontamiento académico fueron utilizados en el presente estudio para evaluar las creencias motivacionales de los estudiantes y las estrategias de afrontamiento.

Resultados. El análisis de conglomerados sugirió cuatro grupos de metas de logro: objetivos orientados a la maestría (enfoque de alto dominio, enfoque de bajo rendimiento y objetivos de evitación), objetivos orientados al rendimiento (enfoque y evitación de alto rendimiento, objetivos de aproximación de dominio moderado), objetivos orientados al enfoque (enfoque de alto dominio y alto rendimiento y menos objetivos para evitar el rendimiento) y altos objetivos orientados múltiples (alto dominio, enfoque de alto rendimiento y objetivos de evitación de alto rendimiento).

Discusión y conclusión. De acuerdo con los resultados, estudiantes con objetivos orientados al enfoque y altos objetivos orientados múltiples tienen más probabilidades de poseer creencias motivacionales adaptativos y usan estrategias de afrontamiento positivas.

Palabras clave: metas multiples, auto-eficacia, valor de la tarea, estrategias de afrontamiento, educación científica. 


\section{Introduction}

One of the important theories of motivation is achievement goal theory. This theory investigates the reasons why people pursue an academic task. For instance, why students want to accomplish a task in science classes is one of the concerns of the theory (Ames, 1992; Urdan, 1997; Pintrich, 2000). The achievement goal researchers suggest that students who are equally motivated to complete a task might have different reasons for doing it (Anderman, Urdan, \&Roeser, 2003). According to early research, there are two achievement goals that can explain reasons of achievement behaviors among students in learning environments: mastery and performance goals: Students adopting mastery goals are in tendency to study to learn and understand the task; while, students with performance goals are likely to study to demonstrate their abilities to others (e.g. Elliot \& Harackiewicz, 1996; Pintrich \& Schunk, 2002). Later, researchers in the field proposed that people may want to achieve a task, to attain a positive namely a desirable possibility, as approach goals, or to avoid a negative eventuality, as avoidance goals. Considering this proposition, four types of achievement goals were shaped: mastery approach goal, mastery avoidance goal, performance approach goal and performance avoidance goal. Students who adopt mastery approach goals aim to improve their skills and knowledge, while students who adopt mastery avoidance goals focus on avoiding misunderstanding of concepts, or failure of learning the lesson. In other words, mastery avoidance goals emphasize avoiding incompetence in their ability or in the task, but improving is not a concern of this orientation (Elliot, 2005). On the other hand, for the students with performance approach goals, the common reason for studying is to demonstrate their skills to other people and to look smart. On the other hand, the common reason to study for students with performance avoidance goals is to avoide getting the worst grade (Elliot\& Thrash, 2001).

According to achievement goal literature, mastery goals are associated with more positive learning outcomes compared to performance goals. More specifically, students who adopt mastery goals tend to select challenging tasks, persist to complete the task and use adaptive learning strategies more than others (e.g. Ames \& Archer, 1988). However, recent studies show that performance approach goals can also be related to positive learning outcomes (e.g. Bong, 2001). Moreover, in some collectivist cultures, performance avoidance goals appeared to be linked to adaptive outcomes (Elliot, Chirkov, Kim, \& Sheldon, 2001). Therefore, researchers turned their attention to investigating achievement goals from a multiple goals perspective. This perspective expects that, both mastery and performance goals can 
result in adaptive outcomes depending on the context. Moreover, Barron and Harackiewicz (2001) proposed that adopting different types of achievement goals simultaneously can be the most adaptive when learning a task. Actually, Barron and Harackiewicz suggested four major advantages of holding multiple goals. In an adaptive goal pattern, mastery and performance approach goals exert independent, significant effects on a single outcome. In an interactive goal pattern, there may be an interaction between mastery and performance approach goals and this interaction creates a positive effect on the learning outcome. In a specialized goal pattern, mastery goals and performance approach goals are positively linked to different outcomes. Lastly, in a selective goal pattern, mastery and performance approach goals are useful in different situations. Several different combinations have been handled by goal researchers so far. On the other hand, there is no consensus yet on which combination of achievement goals has maximum efficient for students in a learning context (Linnenbrink, 2005). Moreover, multiple goal researchers mainly make an emphasis on the combination of approach goals but interaction of approach goals with performance avoidance goals should also be discussed (Pintinch, Conley \& Kempley, 2003). Therefore, in view of the literature, the current study explores middle school students' achievement goals in science from a multiple goals perspective taking performance avoidance goals into consideration in Turkish context.

\section{Achievement Goals and Motivational Beliefs}

As part of motivational beliefs, self-efficacy can be identified as people's beliefs about their own capacity to do a task. In other words, the answer of "Can I do this task?" provides an indication of people's self-efficacy (Bandura, 1977). Task value, on the other hand, involves students' reasons to engage in a task. People's answer of "why should I do this?" provides an indication of their task-value beliefs (e.g. Wigfield \& Eccles, 2000). Students' evaluation about whether they can complete a particular task successfully and their opinions about the quality of task can affect their choice of tasks and persistence. For example, students who think that they can deal with the task effectively are more likely to show effort to complete it. However, students with the belief that they don't have ability to achieve the task are likely to experience fear failure and avoid the task (Bandura 1977). Similarly, students who find the task important, enjoyable or useful appear to spend more exertion to complete the task (Pintrich \& Schunk, 2002).

According to the relevant literature, achievement goals adopted by students are directly affected by their motivational beliefs (Dweck \& Leggett, 1988). For instance, Pintrich 
(2000) investigated students' multiple goals and motivational beliefs in mathematics class. The researcher clustered students' achievement goals into four groups: low mastery/high performance, low mastery /low performance high mastery/low performance and high mastery/ high performance. The researcher reported that students with both high mastery and high performance goals are the most self-efficacious and hold positive task value beliefs. Moreover, performance goals were much more adaptive when combined with mastery goals. In a recent study, Luo, Paris, Hogan, and Luo (2011) examined the relationship of achievement goals to motivational beliefs of Singaporean participants from a multiple goals perspective. The researchers investigated students' goals in four combination: Approach (high mastery, high performance approach and low performance avoidance), Diffuse (moderate multiple), SuccessOriented (high performance approach, high performance avoidance and moderate mastery), and Moderate Mastery (moderate mastery/low performance approach and avoidance) According to the results, the students in approach goals cluster had higher self-efficacy and task value beliefs than the other clusters. Students in success-oriented cluster followed the approach goals. Overall, results suggested that mastery and performance approach goal combination was the most useful for students' learning.

\section{Achievement Goals and Coping Strategies}

People's cognitive, emotional or behavioral response to a negative event like academic failure can be defined as coping (Folkman \& Moskowitz, 2004; Lazarus \& Folkman, 1987). While coping with a negative event, people follow three stages; firstly they realize the event, then they think possible strategies to manage the event, and finally, they perform the action (Lazarus \& Folkman, 1987). According to Tero and Connel (1984), there are different strategies used by students to cope with a failure. These strategies to cope with a negative, stressful event can be classified as positive coping, projective coping, denial coping, and non-coping strategies. Positive coping refers to adaptive strategies like seeking help or finding where the mistake is. In projective coping, students tend to blame others, for their failure. Students who prefer denial coping tend to turn a blind eye on the failure to cope it. Students who use noncoping strategies, on the other hand, blame oneself and feel stupid (Kaplan \& Midgley, 1999).

Researchers in field suggest that achievement goals of students are associated with their use of coping strategies to get through with an academic failure. For instance, Friedel et al. (2007) investigated achievement goals and coping strategies of middle school students. They proposed positive relation between mastery goals and adaptive coping strategies. Re- 
sults, parallel with the expectations, showed that mastery goal oriented students have tendency to use adaptive strategies to cope with an academic failure more often than those with performance goals. Moreover, they are found to use maladaptive coping strategies less frequently than students who adopt performance goals. From multiple goals perspective, Pintrinch (2000) also assessed students' self-handicapping which is also a maladaptive coping strategy. The results revealed a negative relation between mastery goals and self-handicapping. In addition, when performance approach goals are combined with mastery goals, the relationship between maladaptive strategies and performance goals appeared to be weaker.

\section{Motivational Beliefs and Coping Strategies}

According to the relevant literature, students' motivational beliefs are also related to their coping strategies. For example, Mantzicopoulos (1997) investigated the relationship between fourth and fifth grade students' motivation and their coping strategy use. The findings of the study indicated that students who value academic tasks tend to use positive coping more than others. In another study, Hsieh (2005) reported that high task value and selfefficacy beliefs are significantly related to adaptive coping strategy use. Moreover, the study of Devonport and Lane (2006) confirmed previous findings and revealed positive relation between self-efficacy and adaptive coping strategy use. The relevant literature suggests that individuals' motivational beliefs, cognitive outcomes and the relation between these variables may change from culture to culture (e.g. Pintrich, 2003). Hence, students' underlining reasons to pursue an academic task, their adoption of achievement goals may also differentiate the relation between their beliefs and strategy usage when they face an academic failure. To the best of the authors' knowledge, there is no study that investigates the relationship between motivational beliefs and coping strategy use for students from different clusters of achievement goals. Accordingly, current study aims to fill this gap in the literature by examining this relation within the multiple goals perspective.

Actually, although the advantages of multiple goals are clearly indicated in the related literature (Barron \& Harackiewicz, 2001), there is still a need for research on identifying how students combine achievement goals and which combination is helpful for students (Linnenbrink, 2005). Hence, the motivation of this study is to contribute to the multiple goals literature. Moreover, this study aims to investigate coping strategies as potential outcomes of achievement goals so this study could add to the multiple goals perspective of achievement goals due to its investigation of the relation between students' achievement goals and their 
coping strategies. Besides, students' motivation beliefs, achievement goals or cognitive outcomes are not general; they can vary in different domains and in different cultures. Therefore, they should be investigated in domain-specific (Bandura, 1994; Barron \& Harackiewicz, 2000).

\section{Study aims and hypotheses}

In view of the literature, the current study aims to explore students' achievement goals, motivational beliefs and coping strategies in science from a multiple goals perspective. For this purpose, this study will address following research questions:

1) What are Turkish middle school students' profiles (clusters) of achievement goals in science using multiple goals perspective?

2) Are there differences among Turkish middle school students in different cluster of achievement goals with respect to motivational beliefs?

3) Are there differences among Turkish middle school students in different clusters of achievement goals with respect to coping strategy use in science?

4) What are the relationships between motivational beliefs and coping strategy use in science for Turkish middle school students in different clusters of achievement goals?

To investigate afore mentioned research questions following hypotheses will be tested:

1) What are Turkish middle school students' profiles (clusters) of achievement goals in science using multiple goals perspective?

2) There are no differences among Turkish middle school students in different cluster of achievement goals with respect to motivational beliefs.

3) There are no differences among Turkish middle school students in different clusters of achievement goals with respect to coping strategy use in science.

4) There are no relationship between motivational beliefs and coping strategy use in science for Turkish middle school students in different clusters of achievement goals. 


\section{Method}

\section{Participants}

Participants of the study were 317 seventh grade students. The participants are 159 (50. 2\%) female and $158(49.8 \%)$ male students. Most of them were from middle socio economic status families. Majority of participants' fathers (82\%) were employed while majority of the mothers $(85 \%)$ were unemployed. Three-quarter of the participants had less than 100 reading materials in their home.

\section{Instruments}

Motivated Strategies for Learning Questionnaire (MSLQ). Students' motivation and their usage of learning strategies were assessed by the MSLQ, a seven-point Likert scale ranging from "not at all true of me" to "very true of me", developed by Pintrich, Garcia, and McKeachie (1991). It was adapted to Turkish by Sungur (2004). MSLQ contains 15 dimensions. In the current study, only two of the dimensions, namely self-efficacy (e.g. "I expect to do well in this class", $n=8$ items) and task value (e.g. "Understanding the subject matter of this course is very important to me", $n=6$ items) were used. The reliability coefficient of self-efficacy was .89 , and that of task value was .85 in the present study.

Achievement Goal Questionnaire (AGQ). The AGQ, developed by Elliot and McGregor (2001), was used to assess students' adoption of achievement goals. It is a five-point Likert scale ranging from "strongly disagree" to "strongly agree". Senler and Sungur (2007) adapted the questionnaire into Turkish. Three of the AGQ dimensions were used in the current study namely, mastery approach goals (e.g. "I desire to completely master the material that presented in this class", $n=3$ items), performance approach goals (e.g. "It is important to me to do well compare to others in my classes", $n=3$ items) and performance avoidance goals (e.g. "My aim is to avoid doing worse than other students" $n=6$ items). The reliability coefficient of mastery approach goals was .87 , performance approach goals was .92 , while that of performance avoidance goals was .77 for the present study.

Academic Coping Inventory (ACI). Tero and Connell (1984) developed ACI to assess students' coping strategy use in the face of an academic failure. It asks to individuals how much they agree or disagree to the items with a five point Likert scale. There is a stem sentence that is "If something bad happened to me during science, such as doing poorly on a test 
or not being able to answer a question in class" and students are asked to complete it. The ACI consists of 13 items in four dimensions, namely positive coping (e.g. "I would tell myself that I'll do better next time", $n=3$ items), projective coping (e.g. "I would get angry at the teacher", $n=3$ items), denial coping (e.g. "I would say I didn't care about it", $n=3$ items) and non-coping (e.g. "I would feel really stupid", $n=4$ items). The in adaptation study for ACI was conducted by Kahraman (2011). In the current study, the reliability coefficients for positive coping, projective coping, denial coping, and for non-coping were $.70, .80, .78$, and .80 , respectively.

\section{Procedure}

Permissions for this study were asked from the related departments in the University. A paper-pencil survey which included data collection instruments described above and demographic variables were distributed to the students who accepted to participate in the study. Completed questionnaires were returned to the researchers.

\section{Datal Analysis}

As mentioned before, the aim of this study was investigating students' achievement goals motivational beliefs and coping strategies in science from a multiple goals perspective. In the current study, to explore students' multiple goal profile cluster analysis was used. Moreover, MANOVA was used to compare clusters with respect to motivational beliefs and coping strategies. Besides, to investigate the relation between motivational beliefs and coping strategies Canonical correlation analysis was used. All analyses were conducted in SPSS.

\section{Results}

\section{Descriptive Results}

To explore the $7^{\text {th }}$ grade middle school students' profile concerning their achievement goals, motivational beliefs and coping strategy use in science, descriptive statistics were used (see Table 1). According to descriptive results students appeared mainly to adopt both mastery approach $(M=5.58, S D=.52)$ and performance approach goals $(M=4.37, S D=.68)$. They also appeared to have a high level of task value $(M=5.84, S D=1.29)$ and self-efficacy beliefs $(M=5.41, S D=.58)$. Additionally, mean values suggested that they tend to use positive coping strategies $(M=4.54, S D=1.20)$ at higher levels compared to other coping strategies when they face with an academic failure. 


\section{Cluster Analysis}

Cluster analysis was conducted to produce classifications in terms of students' multiple goals. Multiple goal researchers, generally, suggest a four-cluster combination (Dela Rosa \& Bernardo, 2013), hence, a four-cluster solution was chosen in the present study. Since there were hypotheses concerning the number of clusters, k-means clustering method was used for cluster analysis. Descriptive results for each cluster were presented in Table 2.

The first cluster $(n=63)$ involves students who adopt mainly performance goals and moderate mastery approach goals. In other words, students in this group tend to adopt high performance approach, high performance avoidance and moderate mastery approach goals. This cluster was labelled as performance-oriented. Students in the second cluster $(\mathrm{n}=31)$ endorse high mastery approach goals, low performance approach and low performance avoidance goals so this cluster was labelled as mastery-oriented. The third cluster $(n=59)$ was labelled as approach oriented. It involves students who adopt high approach goals, both mastery approach and performance approach, and low performance avoidance goals. Lastly, students who adopt three types of goals at a high level constitute the fourth cluster $(n=164)$ labelled as high multiple oriented.

Table 1 Describtive statistics

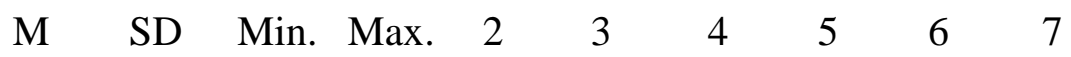
1. Mastery App. Goals
$4.58 \quad .52$
$2.33 \quad 5.00$
$.31^{* *} .19^{* *} \quad .30^{* *} .41^{* *} .43^{* *}-.21^{* *}$
2. Perf. App.
Goals
$\begin{array}{llll}4.37 & .68 & 1.00 & 5.00\end{array}$
$.51^{* *} \quad .25^{* *} .26^{* *} \quad .21^{* *}-.01$
3. Perf. Avo. Goals

$\begin{array}{llll}3.85 & .84 & 1.33 & 5.00\end{array}$
$.14^{* *} .18^{* *} \quad .12^{* *} \quad .07^{*}$
4. Self-Efficacy
$5.41 \quad .58$
$1.00 \quad 7.00$
$.69^{* *} .31^{* *}-.07^{*}$
5. Task value
$\begin{array}{llll}5.84 & 1.29 & 1.00 & 7.00\end{array}$
$.33^{* *}-.17^{* *}$
6. Positive Co- ping
7. Projective Coning 

8. Denial Co- ning
$2.93 \quad 1.27 \quad 1.00 \quad 5.00$
9. Non Coping
3.29
$\begin{array}{lll}1.13 & 1.00 & 5.00\end{array}$

** Correlation is significant at the 0.01 level (2-tailed).

Table 2 Descriptive results of clusters

\begin{tabular}{lcccccc}
\hline & $\begin{array}{c}\text { Mastery Approach } \\
\text { Goals }\end{array}$ & & \multicolumn{2}{c}{$\begin{array}{c}\text { Performance Ap- } \\
\text { proach Goals }\end{array}$} & \multicolumn{2}{c}{$\begin{array}{c}\text { Performance } \\
\text { Avoidance Goals }\end{array}$} \\
& M & SD & M & SD & M & SD \\
\hline $\begin{array}{l}\text { Performance- } \\
\text { oriented }\end{array}$ & 3.89 & .48 & 4.11 & .48 & 3.73 & .37 \\
$\begin{array}{l}\text { Mastery-oriented } \\
\text { Approach oriented }\end{array}$ & 4.21 & .54 & 2.90 & .60 & 2.81 & .58 \\
$\begin{array}{l}\text { High Multiple } \\
\text { oriented }\end{array}$ & 4.84 & .23 & 4.40 & .47 & 2.83 & .61 \\
\hline
\end{tabular}

\section{Achievement Goals and Motivational Beliefs}

In order to determine whether there are differences among Turkish middle school students in different cluster of achievement goals with respect to motivational beliefs, a Multivariate Analysis of Variance (MANOVA) was conducted. According to the results, there were significant differences among four clusters in terms of students' motivational beliefs (Wilks' Lambda $=.79, \mathrm{~F}(3,313)=13.39, \mathrm{p}=.00)$. Bonferroni adjusted alpha level of .025 was used to evaluate group differences. As presented in Table 3, there were statistically significant mean differences among four clusters with respect to self-efficacy and task value beliefs. As shown in Table 4, follow-up testing indicated that students with high multiple oriented goals and approach oriented goals tend to have higher self-efficacy and task value beliefs than the other two (mastery oriented and performance oriented) groups. Moreover, the difference between high multiple oriented and approach oriented groups was not significance in terms of selfefficacy and task value. Besides, there was no significant difference between mastery oriented and performance oriented groups concerning motivational beliefs. 
Table 3 MANOVA Pairwise comparisons

\begin{tabular}{lccc}
\hline Scale & F & P value & Eta Squared \\
\hline Self- efficacy & 20.92 & $.00^{*}$ & .167 \\
Task value & 22.98 & $.00^{*}$ & .181 \\
\hline
\end{tabular}

* The mean difference is significant at the .025 level (.05/2)

Table 4 Means and significances of clusters

\begin{tabular}{|c|c|c|c|c|}
\hline \multicolumn{2}{|c|}{$\underline{\text { Performance-oriented }}$} & \multirow{2}{*}{$\begin{array}{l}\underline{\text { Mastery- }} \\
\underline{\text { oriented }} \\
\mathrm{M}(\mathrm{SD})\end{array}$} & \multirow{2}{*}{$\begin{array}{c}\frac{\text { Approach orien- }}{\underline{\text { ted }}} \\
\mathrm{M}(\mathrm{SD})\end{array}$} & \multirow{2}{*}{$\begin{array}{c}\frac{\text { High Multiple }}{\text { oriented }} \\
\text { M (SD) }\end{array}$} \\
\hline & $\mathrm{M}(\mathrm{SD})$ & & & \\
\hline Self-Efficacy & $4,69(1.20)^{1}$ & $4,47(1.54)^{1}$ & $5,71(1.13)^{2}$ & $5,75(1.10)^{2}$ \\
\hline Task Value & $5,04(1.31)^{1}$ & $5,26(1.14)^{1}$ & $6,08(1.02)^{2}$ & $6,17(.87)^{2}$ \\
\hline
\end{tabular}

*The same superscript of 1, 2 demonstrates that these groups are not statistically different from each other on the dependent variables

\section{Achievement Goals and Coping Strategies}

In order to examine whether there are differences among Turkish middle school students in different clusters of achievement goals with respect to coping strategy use in science, a Multivariate Analysis of Variance (MANOVA) was used. The results indicated that there were significant differences among four clusters in terms of coping strategy use (Wilks' Lambda $=.80$, $\mathrm{F}(3,313)=6.10, \mathrm{p}=.00)$. Bonferroni adjusted alpha level of .0125 was used to evaluate group differences. 
As presented in Table 5, there were statistically significant mean differences among clusters with respect to positive coping and non-coping, and no significant differences were found concerning projective coping and denial coping. As shown in Table 6, follow-up testing indicated that students who adopt high multiple and approach oriented goals use positive coping strategies at higher levels than both mastery oriented and performance oriented students. The difference between mastery oriented and performance oriented students in terms of positive coping strategy use was not statistically significant. Concerning non-coping strategies, students with high multiple oriented and performance oriented goals were found to use noncoping strategies at higher levels compared to mastery oriented and approach oriented students.

Table 5 The Pairwise comparisons

\begin{tabular}{lccc}
\hline Scale & $\mathrm{F}$ & $\mathrm{P}$ value & Eta Squared \\
\hline Positive Coping & 18.82 & $.00^{*}$ & .153 \\
Projective Coping & 1.12 & .342 & .011 \\
Denial Coping & .10 & .958 & .001 \\
Non-coping & 6.70 & $.00^{*}$ & .060 \\
\hline
\end{tabular}

$*$ The mean difference is significant at the $.012(.05 / 4)$ level

Table 6 Means and significances of clusters

\begin{tabular}{|c|c|c|c|c|}
\hline \multicolumn{2}{|c|}{ Performance-oriented } & \multirow{2}{*}{$\begin{array}{l}\frac{\text { Mastery- }}{\underline{\text { oriented }}} \\
\mathrm{M}(\mathrm{SD})\end{array}$} & \multirow{2}{*}{$\begin{array}{l}\text { Approach oriented } \\
\text { M (SD) }\end{array}$} & \multirow{2}{*}{$\begin{array}{l}\text { High Multiple } \\
\underline{\text { oriented }} \\
\text { M (SD) }\end{array}$} \\
\hline & $\mathrm{M}(\mathrm{SD})$ & & & \\
\hline Positive coping & $4,19(.64)^{1}$ & $4,19(.67)^{1}$ & $4,60(.52)^{2}$ & $4,71(.46)^{2}$ \\
\hline $\begin{array}{l}\text { Projective co- } \\
\text { ping }\end{array}$ & $2,86(1.12)^{1}$ & $2,44(1.05)^{1}$ & $2,52(1.31)^{1}$ & $2,57(1.38)^{1}$ \\
\hline Denial coping & $2,99(1.15)^{1}$ & $2,89(.99)^{1}$ & $2,96(1.24)^{1}$ & $2,90(1.25)^{1}$ \\
\hline
\end{tabular}




$\begin{array}{llll}\text { Non-coping } \quad 3,37(.98)^{2} & 2,63(.86)^{1} & 3,01(1.69)^{1} & 3,48(1.17)^{2}\end{array}$

*The same superscript of 1, 2 demonstrates that these groups are not statistically different from each other on the dependent variables

\section{Relation between motivational beliefs and coping strategies}

To investigate the relation between students' motivational beliefs (self-efficacy and task value) and their coping strategy (positive coping, projective coping, denial coping and non-coping) use for each cluster, 4 canonical correlation analyses were performed. Canonical correlation was not significant for performance oriented group, $\mathrm{F}(8,116)=1.95, p=.059$, and for approach oriented group $F(8,106)=1.31, p=.245$. On the other hand, canonical correlation was significant between two sets of variables for mastery oriented groups $F(8,50)=2$. $32, p<.005$. The first canonical correlation was .65 (42\% overlapping variance) accounting for the significant relationships between the two sets of variables. Besides, canonical correlation was significant between two sets of variables for high multiple oriented groups $F(8,316)$ $=5.50, p<.005$. The first canonical correlation was .41 (17\% overlapping variance) accounting for the significant relationships between the two sets of variables. For both groups, as shown in table 7, with a cut off correlation of .30 (Tabachnick \& Fidell, 2013), two of the variables in the motivational beliefs set were positively correlated with the first canonical variate. Regarding to coping strategies variable, positive coping was found to be positively, projective and denial coping were found to be negatively related to first canonical variate, while, non-coping failed to reach significance. The first pair of canonical variates showed that, for both mastery oriented and high multiple oriented students, higher levels of task value and self-efficacy beliefs were associated with higher levels of positive coping strategy use. On the other hand, the relations between these motivational beliefs and use of projective and denial coping strategies were negative.

Table 7 Correlations, standardized canonical coefficients, canonical correlations, percent of variance, and redundancies

Mastery oriented

Correlation Coefficient Correlation
High multiple oriented

Coefficient 
SET 1: Motivation

Task value .85

.08

.95

1.20

Self-efficacy

.99

.93

.38

$-.40$

Percent of

86.27

52.79

variance

Redundancy

37.07

8.70

SET 2: Coping strategies

Positive coping

Projective coping

Denial coping

Non coping

Percent of variance

.02

34.08
.36

$-.90$

$-.44$

$-.11$

.04

28.64

4.76
.34

$-1.05$

.14

.18

\begin{tabular}{ccc} 
Redundancy & 14.65 & 4.76 \\
\hline Canonical correlation & .65 & .41
\end{tabular}

\section{Discussion and Conclusions}

The purpose of the present study was to explore middle school students' achievement goals in science from a multiple goals perspective. Although most of the multiple goal researchers have focused on the relationship between mastery approach and performance approach combinations, the relevant literature suggest that performance avoidance goals should be considered, too (Pintrinch, Conley \& Kempley, 2003). Hence, three of the achievement goals, mastery approach, and performance approach and avoidance goals were examined in the current study. To classify students' achievement goals, cluster analysis was conducted. Four goal combinations were identified i.e. Approach oriented (high mastery approach, high performance approach, low performance avoidance), Performance-oriented (moderate mastery approach, high performance approach and avoidance), Mastery-oriented (high mastery ap- 
proach, low performance goals) and High multiple oriented (high mastery approach, performance approach and avoidance). According to the results, the high multiple oriented cluster includes the highest number of participants for this sample. This finding suggests that Turkish middle school students tend to adopt three types of goals simultaneously when learning science that is., they are likely to study science to master the task, to demonstrate their abilities as well as to avoid leaving an impression of failure.

In order to identify which combination of achievement goals (cluster) is more adaptive for the achievement related outcomes in science classes, the differences among the students in different clusters of achievements goals with respect to motivational beliefs and coping strategies were investigated. Self-efficacy and task value were considered as students' motivational beliefs. Moreover, coping strategies were investigated in four dimensions: positive, projective, denial and non-coping. While positive coping represents an adaptive coping strategy, projective, denial and non-coping represent maladaptive coping strategies. According to the results, high multiple oriented and approach oriented students appeared to be more selfefficacious and believe that science task and activities are interesting, useful, and important. In addition, they appeared to use positive coping strategies such as re-trying or persisting on the task when they face a stressful event while learning science at higher levels. In parallel with these findings, multiple goal researchers offered that students who combine mastery goals with performance goals are likely to have positive learning outcomes (Barron \& Harackiewicz, 2001). For example, in a recent research, Luo et al. (2011) examined goal combinations and reported that Singaporean students who combine mastery goals with performance goals, especially performance approach goals, tend to hold adaptive motivational beliefs. Success-oriented goals (moderate mastery, high performance approach and avoidance goals) followed approach goals in terms of motivational beliefs. This finding was not in congruence with the traditional achievement goal theory (e.g. Ames \& Archer, 1988) which expects negative relations between performance avoidance goals and adaptive outcomes (e.g. Ames \& Archer, 1988). These findings can be partly explained by cultural factors: Singapore's culture is a little bit similar to Turkish culture in that they show the characteristics of both collectivist and individualistic cultures. In collectivistic cultures people's definition of their identity depends on society (Kağıtçıbaşı, 1994); therefore, in these cultures, it is not surprised that performance avoidance are linked to positive outcomes (Elliot, et al., 2001). Thus, in such cultures, it is reasonable to find that students who study to understand the task, to show their abilities to others and to avoid looking stupid tend to perceive the science tasks useful, enjoyable 
or interesting, and believe that they can achieve a science task and tend to use adaptive coping strategies to cope a failure in science. Additionally, why performance avoidance goals didn't negatively affect the students' adaptive outcomes might have resulted from Turkish educational system: Turkish education system is test-oriented and supports competition among students. The competitive environment may lead students to focus on avoiding worse grades, so the combination of three types of goal can be more beneficial for students in terms of adaptive learning outcomes (Sungur \& Senler, 2009).

On the other hand, the effect of combined achievement goals on maladaptive coping strategies produced a different profile. Firstly, four clusters didn't show significant differences in terms of using denial coping and projective coping strategies. Regarding non-coping strategies, students with mastery-oriented and approach oriented goals appeared to have tendency to use less maladaptive strategies to cope with a stressful academic event in science. Put it differently, students who focus on learning the task and improving their skills, or who combine the purpose of mastering the task with the aim of getting high grades tend to exhibit less non-coping behaviors like blaming themselves for the failure. The results also suggest that high multiple oriented goals were not significantly different from performance-oriented goals in using non-coping strategies and students in these two clusters tend to adopt noncoping strategies more than students in mastery orientated goals and approach oriented goals clusters. The common point of high multiple oriented and performance oriented clusters is that both clusters have higher performance avoidance goals than the other clusters. Thus, this finding was in line with the traditional achievement goal theory literature which suggests a positive association between performance avoidance goals and maladaptive coping strategies (e.g. Friedel et al, 2007). At this point, it is important to note that according to the current findings students within clusters of higher levels of performance avoidance goal together with other goals tend to use positive coping as well as non-coping strategies at higher levels. These findings point out that although the unexpected positive link, according to the traditional achievement goal theory, between high performance avoidance goals and positive coping strategy use can be partly explained by cultural and contextual factors, the expected link emerged in the current study between high performance avoidance goals and non-coping strategy use suggest that even in certain cultures and context performance avoidance goals may not lead to adaptive outcomes in science consistently. 
Besides, in the current study, in order to investigate the relationships between motivational beliefs and coping strategy use in science for Turkish middle school students in different clusters of achievement goals, canonical correlations were performed for each group separately. While the mentioned relations were significant for mastery oriented and high multiple oriented goals, it did not reach the significance for approach oriented and performance oriented goals. For mastery oriented and high multiple oriented students, higher level of selfefficacy and task value beliefs were found to be related to higher level of positive coping, and lower level of projective and denial coping strategies. Actually, the descriptive results of the current study also revealed that approach oriented and high multiple oriented students tend to have higher levels of adaptive motivational beliefs and use positive coping strategies at higher levels while using maladaptive strategies at lower levels. Overall, current findings suggest that students with approach oriented goals and high multiple oriented goals are more likely to possess adaptive motivational beliefs and use positive coping strategies in science. More specifically, according to the findings the combination of mastery goals with both approach and avoidance performance goals can be conducive to Turkish students' science learning. However, considering theoretical expectations and some of the empirical findings in the relevant literature, it is still suggested that the level of avoidance goals adopted by the students should not be too high. Actually, the present study also suggested that the link between performance avoidance goals and adaptive outcomes may not show a consistent pattern even in certain contexts (e.g. competitive educational system, collectivist cultures). Thus, the main implication of the current study taking the relevant literature into consideration is that science teacher should emphasize approach goals especially mastery approach goals in their classes. In order to do this, they can introduce students with a variety of science task and activities which are relevant to their lives and meaningful. In addition, students should experience a sense of control over their learning and should be able to realize the link between their efforts and improvements in learning science concepts (Pintrich \& Schunk, 2002)

There are some limitations of the study that need to be acknowledged. First, this study doesn't suggest cause-and-effect relation since it has a cross-sectional design. Experimental or longitudinal studies can be conducted to investigate the relation of multiple goals to motivational beliefs and coping strategies to propose cause-and-effect relation. Second, the participants of this study involve only $7^{\text {th }}$ grade students from Turkey. Therefore, the mentioned relationship may vary according to different grades and cultures. The other limitation of the 
study is that students' achievement goals and their learning outcomes were assessed only for science domain. Different results may be obtained in different domains.

\section{References}

Ames, C. (1992). Classrooms: Goals, structures, and student motivation. Journal of educational psychology, 84(3), 261.

Ames, C., \& Archer, J. (1988). Achievement goals in the classroom: Student's learning strategies and motivation processes. Journal of Educational Psychology, 80 (3), 260267.

Anderman, E.M. \&Urdan, T. \&Roeser, R. (2003). The patterns of adaptive learning survey: History, development, and psychometric properties. For Indicators of Positive Development Conference, March 12-13, 2003.

Bandura, A. (1977). Self-efficacy: Toward a unifying theory of behavioral change. Psychological Review, 84, 191-215.

Barron, K. E., \& Harackiewicz, J. M. (2001). Achievement goals and optimal motivation: testing multiple goal models. Journal of personality and social psychology, 80(5), 706.

Bong, M. (2001). Between-and within-domain relations of academic motivation among middle and high school students: self-efficacy, task-value, and achievement goals. Journal of Educational Psychology, 93(1), 23-34. https://doi.org/10.1037/0022-0663.93.1.23.

Dela Rosa, E. D., \& Bernardo, A. B. (2013).Testing Multiple Goals Theory in an Asian Context: Filipino University Students' Motivation and Academic Achievement. International Journal of School \& Educational Psychology, 1(1), 47-57. https://doi.org/10.1080/21683603.2013.782594.

Devonport, T. J., \& Lane, A. M. (2006). Relationships between self-efficacy, coping and student retention. Social Behavior and Personality: an international journal, 34(2), 127-138. https://doi.org/10.2224/sbp.2006.34.2.127.

Dweck, C.\& Leggett, E., L. (1988). A social- cognitive approach to motivation and personality. Psychological Review, 95, 256-273.

Elliot, A. J., Chirkov, V. I., Kim, Y., \& Sheldon, K. M. (2001). A cross-cultural analysis of avoidance (relative to approach) personal goals. Psychological Science, 12(6), 505510. https://doi.org/10.1111/1467-9280.00393. 
Elliot, A.J. \&Harackiewicz J.M. (1996). Approach and avoidance achievement goals and intrinsic motivation: a mediational analysis. Journal of Personality and Social Psychology, 70(3), 461-475.

Elliot, A. J. (2005). A conceptual history of the achievement goal construct. In A. Elliot \& C. Dweck (Eds.), Handbook of competence and motivation (pp. 52-72). New York: Guilford Press.

Elliot, A.J., \& McGregor, H.A. (2001). A 2 X 2 achievement goal framework. Journal of Personality and Social Psychology, 80, 501-519. https://doi.org/10.1123/jsep.25.4.456.

Folkman, S., \& Moskowitz, J. T. (2004). Coping: Pitfalls and promise. Annu. Rev. Psychol., $55,745-774$.

Elliot, A.J., \& Thrash, T.M. (2001). Achievement goals and hierarchical of achievement motivation. Educational Psychology Review, 13, 139-156. https://doi.org/10.1023/A:1009057102306.

Friedel, J. M., Cortina, K. S., Turner, J. C., \&Midgley, C. (2007). Achievement goals, efficacy beliefs and coping strategies in mathematics: The roles of perceived parent and teacher goal emphases. Contemporary Educational Psychology, 32(3), 434-458. https://doi.org/10.1016/j.cedpsych.2006.10.009.

Harackiewicz, J. M., Barron, K. E., Carter, S. M., Lehto, A. T., \& Elliot, A. J. (1997). Predictors and consequences of achievement goals in the college classroom: Maintaining interest and making the grade. Journal of Personality and Social psychology, 73(6), 1284. 10.1037/0022-3514.73.6.1284.

Kahraman, N. (2011). Antecedents and consequences of achievement goals (Doctoral Dissertation, Middle East Technical Unıversity).

Kamins, M. L., \&Dweck, C. S. (1999). Person versus process praise and criticism: implications for contingent self-worth and coping. Developmental psychology, 35(3), 835. http://dx.doi.org/10.1037/0012-1649.35.3.835.

Kaplan, A., \&Midgley, C. (1999). The relationship between perceptions of the classroom goal structure and early adolescents' affect in school: The mediating role of coping strategies. Learning and Individual Differences, 11(2), 187-212. https://doi.org/10.1016/S1041-6080(00)80005-9.

Lazarus, R. S., \&Folkman, S. (1987). Transactional theory and research on emotions and coping. European Journal of personality, 1(3), 141-169. doi:10.1002/per.2410010304. 
Linnenbrink, E. A. (2005). The Dilemma of Performance-Approach Goals: The Use of Multiple Goal Contexts to Promote Students' Motivation and Learning. Journal of educational psychology, 97(2), 197. doi:10.1037/0022-0663.97. 2.197.

Luo, W., Paris, S. G., Hogan, D., \& Luo, Z. (2011). Do performance goals promote learning? A pattern analysis of Singapore students' achievement goals. Contemporary Educational Psychology, 36(2), 165-176. https://doi.org/10.1016/j.cedpsych.2011.02.003.

Pintrich, P.R. (2000). Multiple goals, multiple pathways: the role of goal orientation in learning and achievement. Journal of Educational Psychology, 92(3), 544555.https://www.doi.org/10.1037/0022-0663.92.3.544.

Pintrich, P. R. (2003). A motivational science perspective on the role of student motivation in learning and teaching contexts. Journal of educational Psychology, 95(4), 667. http://dx.doi.org/10.1037/0022-0663.95.4.667.

Pintrich, P. R., Conley, A. M., \&Kempler, T. M. (2003). Current issues in achievement goal theory and research. International Journal of Educational Research, 39(4), 319-337.

Pintrich P., Smith D., Garcia T., McKeachie W. (1991). A Manual for the Use of the Motivated Strategies for Learning Questionnaire. Technical Report 91-B-004. The Regents of The University of Michigan.

Printrich, P.,,R.\&Schunk, D., H. (2002). Motivation in education: theory, research and applications. Ohio: Merrill Prentice Hall.

Sungur, S. (2004). An implementation of problem based learning in high school biology courses (Doctoral dissertation, METU).

Sungur, S., \& Senler, B. (2009). An analysis of Turkish high school students' metacognition and motivation. Educational Research and Evaluation, 15(1), 45-62. https://doi.org/10.1080/13803610802591667.

Senler, B. \& Sungur, S. (2007) November. "Hedef Yonelimi Anketinin Turkce’ ye Cevrilmesi ve Adaptasyonu [Translation and Adaptation of Achievement Goals Questionnaire to Turkish]."

Tero, P. F., \& Connell, J. P. (1984). When children think they've failed: An academic coping inventory. Unpublished manuscript, University of Rochester.

Urdan, T.C., (1997). Examining the relations among early adolescent students' goals and friends' orientation toward effort and achievement in school. Contemporary Educational Psychology, 22, 165-191. https://doi.org/10.1006/ceps.1997.0930. 
Effects of Achievement Goals on Students' Motivational beliefs and Coping Strategies: A Multiple Goals Perspective

Wigfield, A., \& Eccles, J. S. (2000). Expectancy-value theory of achievement motivation. $\begin{array}{llll}\text { Contemporary educational } & \text { 25(1), }\end{array}$ https://doi.org/10.1006/ceps.1999.1015. 